\title{
What Is Computer Science?
}

In a rcent article published in Elektronische Rechenanlagen (Vol. 13, No. 4, 1971, pp. 15i-161), Dr. H. Zemanck, the current president of IFIP, suggests four main problem areas as central to computer science:

(1) a theory of programming, with emphasis not mainly on the problems of distinguishing the computable from the noncomputable, but rather on a practical theory of algorithms concerned with the construction of economical and efficicnt programs;

(2) a theory of process and processor organization, which takes into account the finite dimensions of existing memories, the availability of storage hierarchies of varying access specds and costs, and the desire for a reduction in computation and program production time;

(3) a theory of description for processes and computational structures in terms acceptable to the processor; and

(t) a theory of computer applications which would include all features common to most numeric and nonnumeric applications.

In the light of these proposed specifications for the computer science field, it may be of inter'st to investigate whether any major changes may have occurred in the computer litcrature orcr the past few years. Consider, as an example, the materials published in the ACXI Journal in the years 1969 and 1971, respectively, as reflected by the cumulative indexes in the October 1969 and October 1971 issues of $J . A C M$. The following trends are immediately noticeable:

(l) the papers on formal language theory, parsing, and compiler design have largely been replaced by material on program organization and operating systems, including, in particular, parallel processing methods, scheduling, paging, and general process organization;

(2) the work on automata and abstract machine theory is reduced in scope and replaced by material dealing with the theory of computation, including the dcsign of efficient or correct programs, the complexity and completeness of algorithms, and the mathematical analysis of algorithms;

(3) a continued emphasis-some would say overemphasis-on numerical mathematics is apparent, including materials concerned with techniques of numerical analysis, theorem proving, and the execution of computerized mathematics;

(4) the continued near-total absence of material dealing with nonnumeric applications-including systems for management and administration, applications to science and the humanities, and technological applications-is obrious; and

(5) the area of hardware and processor organization continues to be neglected.

How do thrse drvlopments match Dr. Zemanek's prescription for a computer scince discipline? In part, the match is quite close. A great deal of progress is certainly apparent in programming and complexity theory, leading to a better un.

Coprright $\bigcirc$ 1972, Association for Computing Machinery, Ine.

(ieneral permission to republish, but not for profit, all or part of this material is granted rovided that reference is made to this publication, to its date of issue, and to the fact that aprinting privileges were granted by permission of the Association for Computing Machinery.

Irnul of the Assuciution for Computing Machinery, Vol. 19, No. 1, January 1972, pp. 1-2. 
derstanding of many types of algorithms. Furthermore, the work in operating systems may in time lead to a respectable theory of process organization. A theory of description is still lacking, but interest continues in the development and manipulation of efficient data structures. The prospects appear least favorable for the generation of a theory of applications: although quite a bit is known about the processes which enter in to the solution of nonnumeric computer applications-pattern matching techniques, smoothing procedures, clustering and classification methods-and some understanding exists of file organization and file accessing methodologies, the thread that would pull it all together is absent, and no indication of a breakthrough is apparent.

Where does this leave the computer science area? For some years, the main interest may continue to be concentrated in the theory of computation and the problems of program and process organization. The recent developments in new processor organizations, including, in particular, the computer networks and interactive processing techniques, may also cause an upsurge of interest in the hardware area. Finally, new advances in the applications areas-leading eventually to some generalized approaches to nonnumeric computer applications-must be expected. New discoveries, and changes in emphasis within the various subareas, are certain to be reflected promptly by alterations in the coverage of the computer journals and the proceedings of major conferences-witness the apparent decrease of interest within the space of two years in compiler design and the theory of formal languages.

What then about the charge which may occasionally be heard (for example in Comm. ACM editorials) that the scientific conferences and journals do not reflect the happenings in the field, that a lack of communication is apparent between researchers on the one hand and designers and operators on the other, and that academics are frustrated because the proven technology is being ignored or misused? Even if true, this observer cannot believe that much harm actually results. The computing practice is bound to lag somewhat behind the relevant theoretical advances, and present practice is not the same as it was five years ago, any more than the journal coverage is the same now as earlier. Furthermore, in the near future, an increasing proportion of scientists with advanced degrees in computer science is likely to wind up in positions outside the universities, thereby narrowing the alleged gap between theory and practice still further.

The best bet for a rapid advance in computer scicnce, as elsewhere, continues to be the availability of strong investigators, together with first-rate journals and seientific meetings to disseminate the knowledge which may be gained.

-G. Salton 